\title{
DRY NEEDLING AS A PAIN MODULATING MODALITY IN MYOFASCIAL PAIN SYNDROME
}

\author{
N. Ravinder Kumar'1, Kali Vara Prasad Vadlamani², G. V. S. Moorty³, D. Nirmala4 ${ }^{4}$ B. Janaki Rama Sarma ${ }^{5}$
}

${ }^{1}$ Associate Professor, Department of Orthopaedics \& Traumatology, Osmania General Hospital/Osmania Medical College, Hyderabad. ${ }^{2}$ Associate Professor, Department of Orthopaedics \& Traumatology, Osmania General Hospital/Osmania Medical College, Hyderabad. 3Professor, Department of Orthopaedics \& Traumatology, Osmania General Hospital/Osmania Medical College, Hyderabad. ${ }^{4}$ Physiotherapist, Department of Orthopaedics \& Traumatology, Osmania General Hospital/Osmania Medical College, Hyderabad. ${ }_{5}^{5}$ Physiotherapist, Department of Orthopaedics \& Traumatology, Osmania General Hospital/Osmania Medical College, Hyderabad.

\section{ABSTRACT}

\section{BACKGROUND}

Myofascial Pain Syndrome (MPS) is a significant health problem affecting as much as $85 \%$ of the general population, sometime in their lifetime, while the estimated overall prevalence is 46\%. Low back pain is the most common MPS affecting all age groups with no gender discrimination. It can be acute or chronic. It can cause localised, diffuse, radicular or referred type of pains. Dry Needling or intramuscular stimulation is a skilled intervention that uses a thin filiform needle to penetrate the skin and stimulate underlying myofascial trigger points, muscular and connective tissues for the management of neuromusculoskeletal pain and movement impairments in Myofascial Pain Syndrome (MPS).

\section{MATERIALS AND METHODS}

90 patients (57 male and 33 female) who attended the Department of Physio-Occupation Therapy, which is a part of the Department of Orthopaedics, Osmania General Hospital, were randomly chosen after clearance from the Ethical Committee. The study period extended from June 2015 to Jan 2016. They were divided into groups according to their position in Visual Analogue Scale (VAS) and their respective scores were noted. Their scores were once again noted after they received the Dry Needling treatment of about 6 sittings.

\section{RESULTS}

Out of the 90 cases, 65 cases showed excellent results (VAS 0-1 after treatment), 18 cases showed good results (VAS 2-3 after treatment), 6 cases showed fair results (VAS 4-5 after treatment), 2 cases showed VAS- 6 after treatment.

\section{CONCLUSION}

Dry Needling is a relatively new treatment modality with specific subjective pain modulation efficacy in myofascial pain syndrome, which can help us in alleviating the pain in chronic conditions and acts adjuvant to the specific treatment.

\section{KEYWORDS}

Dry Needling, Myofascial Pain Syndrome (MPS), Myofascial Trigger Points, VAS.

HOW TO CITE THIS ARTICLE: Kumar NR, Vadlamani KVP, Moorty GVS, et al. Dry needling as a pain modulating modality in myofascial pain syndrome. J. Evolution Med. Dent. Sci. 2016;5(44):2777-2780, DOI: 10.14260/jemds/2016/648

\section{INTRODUCTION}

Myofascial pain syndrome is defined as pain of muscular origin that originates in a painful site in muscle. This site is characterized by the myofascial trigger points. It is defined by its physical (motor) characteristics and by its sensory features. Not all of the motor and sensory features of the trigger points need to be present to identify it clinically.

A myofascial "Trigger Point" (TP) is a hyperirritable point in skeletal muscle that is associated with a hypersensitive palpable nodule or "knot." Myofascial Pain Syndrome (MPS) is caused by myofascial Trigger Points (TPs) located within taut bands of skeletal muscle fibres. Treating the underlying aetiologic lesion is most important.

Yet treatment of active TPs may be necessary in situations in which active TPs persist even after the underlying aetiologic lesion has been appropriately treated. ${ }^{1}$

Financial or Other, Competing Interest: None.

Submission 17-04-2016, Peer Review 11-05-2016,

Acceptance 17-05-2016, Published 02-06-2016.

Corresponding Author:

Dr. Kali Vara Prasad Vadlamani,

F 12, Sneha Enclave,

St. No. 4, West Maredpally,

Secunderabad.

E-mail:prasadvkv@gmail.com

DOI: $10.14260 /$ jemds $/ 2016 / 648$
Trigger points are physiological contractures characterised by local ischemia, hypoxia, significantly lower $\mathrm{pH}$, altered chemical milieu, local and referred pain and altered muscle activation pattern. This area becomes painful at the site and can also "radiate" in predictable patterns known as referred pain. Trigger points may be of two types - Active and Latent. An active TP exhibits spontaneous pain or pain in response to movement, stretch or compression, while a latent $\mathrm{TP}$ is a sensitive spot with pain or discomfort in response to compression only.

Dry Needling is a technique, which involves the use of either solid filiform needles (Also referred to as acupuncture needles) or hollow-core hypodermic needles for alleviation of chronic muscle pain including pain related to myofascial pain syndrome through Intramuscular Stimulation (IMS).

Dry Needling causes a Local Twitch Response (LTR) by stimulating the concerned muscle. LTR is spinal cord reflex that is characterised by a momentary involuntary contraction of the muscle. This leads to relaxation of shortened taut bands of muscle fibres, which can be elicited by snapping palpation. Eliciting this local twitch response is a key for successful deactivation of the trigger point, which releases muscle tension and lessens the pain to bring immediate relief of symptoms. 


\section{DRY NEEDLING MODULATES SUBJECTIVE PAIN SENSATION THROUGH THE FOLLOWING EFFECTS Effects on the Taut Band}

Insertion of a needle at the endplate region may lead to increased discharges leading to elicitation of LTRs and reduction of available acetylcholine stores. LTR causes alterations in the length and tension of the muscle fibres and stimulates mechanoreceptors like the $A \beta$-fibres. ${ }^{2}$

\section{Effects on Blood Flow}

Dry Needling may increase muscle blood flow and oxygenation countering the local ischemia and hypoxia in the core of the TPs caused by sustained contractures of taut muscle bands. Probably, the release of vasoactive substance such as CGRP and Substance $\mathrm{P}(\mathrm{SP})$ which upon activation of $\mathrm{A} \delta$ - and C-fibres via the axon reflex lead to vasodilatation of small vessels, thus increasing the blood flow. ${ }^{3}$

\section{NEUROPHYSIOLOGICAL EFFECTS}

\section{Effects on Peripheral Sensitization}

Shah et al ${ }^{4,5}$ found that the concentrations of SP and CGRP were higher in the vicinity of active TPs compared to latent ones or normal muscle tissue. After a LTR was elicited, SP and CGRP concentrations were significantly lowered compared to their pre-LTR values. These values were consistent with the data of Hsieh et al. ${ }^{6} \mathrm{~A}$ single session treatment produced a short-term analgesic effect by decreasing the SP at peripheral sites.

\section{Effects on Central Sensitization}

The most likely mechanism of pain relief through needle stimulation is hyperstimulation analgesia. DN probably stimulates both large myelinated fibers (A $\beta$ - and $A \delta$-fibers) as well as $\mathrm{C}$-fibers indirectly via the release of inflammatory mediators. As a result of mechanical stimulation, $\mathrm{A} \beta$ - and $\mathrm{A} \delta$ fibers are both activated and send afferent signals to the dorsolateral tracts of the spinal cord and activate the supraspinal and higher centres involved in pain processing. 7,8,9,10

The advantages of Dry Needling are many. Quicker results, no drugs, symptomatic relief, cost effectiveness, treatment of deeper layers of muscle, parts of the muscle all make it an excellent pain modulating procedure.

Our study was an attempt at establishing the pain modulating efficacy of Dry Needling, as it is simple yet effective technique for providing symptomatic relief from chronic muscular pain.

\section{MATERIALS AND METHODS}

90 patients (57 male and 33 female, age range from 20 years to 60 years) who attended the Department of PhysioOccupation Therapy, which is a part of the Department of Orthopaedics, Osmania General Hospital were randomly chosen. The study period extended from June 2015 to Jan 2016, a minimum of 4-6 sittings were given.

\section{Inclusion Criteria}

- Pts. between the ages 20-70 yrs.

- Pts. whose pain is not relieved with traditional physiotherapy methods

- $\quad$ Pts. with VAS score not less than 5.

\section{Exclusion Criteria}

Patients with paraesthesia, anxiety, renal failure, cardiac failure, uncontrolled diabetes, vascular diseases like haemophilia or on blood thinning medications.

A comparative Visual Analogue Scale (VAS) was used to divide the subjects into 6 groups according to their position in the scale. The patients were so selected that they had chronic pain in the muscles of the back and were placed after position 5 in the scale. Moreover, all of them were not getting pain relief with traditional mode of treatment. Dry Needling treatment was given after identifying the major trigger points of the back (Diagram 1, 2).

A VAS is a simple and frequently used method for the assessment of variations in intensity of pain. In clinical practice the percentage of pain relief assessed by VAS is often considered as a measure of the efficacy of treatment; $2 \mathrm{~A}$ Operationally VAS is a pain rating scale anchored by word descriptors at one side and facial illustration on the other side. ${ }^{11}$ (Diagram 3).

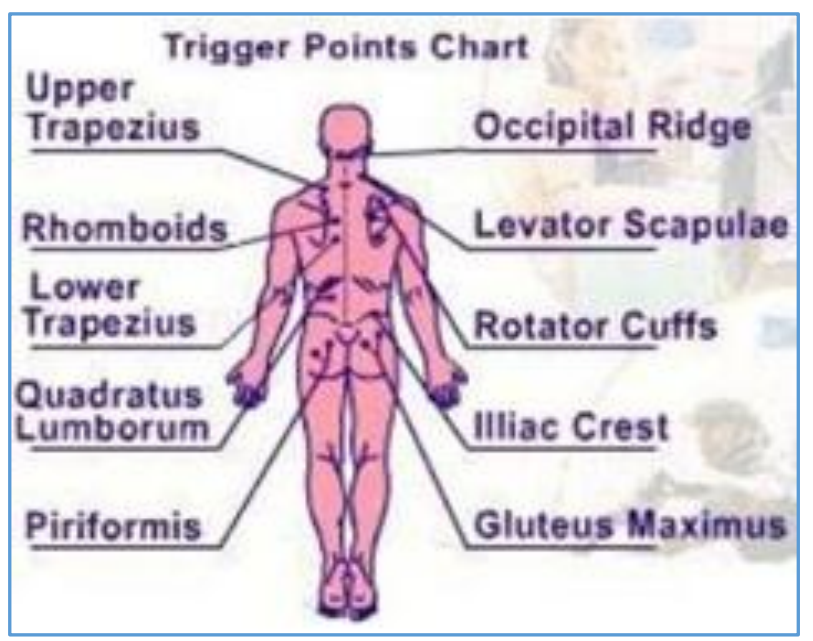

Diagram 1: Position of Some Trigger Points

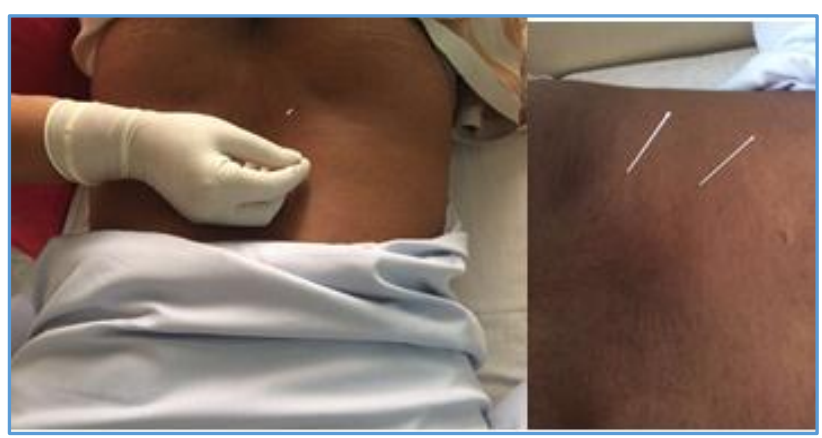

Diagram 2: Dry Needling Procedure

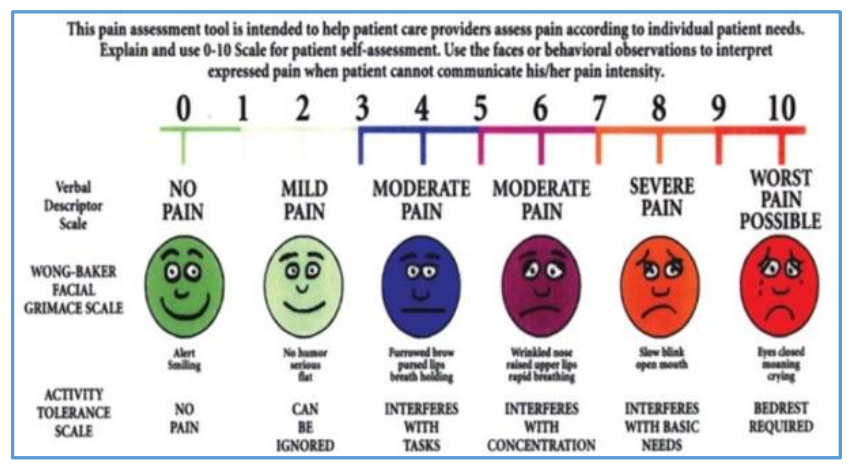

Diagram 3: Visual Analogue Scale 


\section{RESULTS}

Out of the 90 cases, 65 cases showed excellent results (VAS 01 after treatment), 18 cases showed good results (VAS 2-3 after treatment), 5 cases showed fair results (VAS 4-5 after treatment).

2 cases showed VAS- 6 (Table 1, Chart 1 ).

Using suitable SPSS software, the observed values were compiled and $P$ value was determined.

$P$ value was less than 0.005 , which indicated that the correlation of Dry Needling procedure and subjective relief from pain was highly significant.

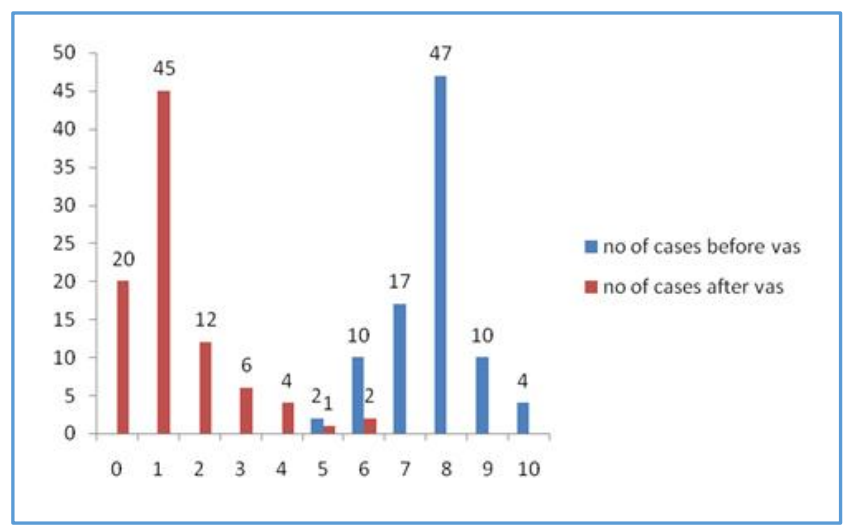

Chart 1: Comparison of Vas Before \& After Procedure

\begin{tabular}{|c|c|c|c|}
\hline $\begin{array}{c}\text { Number of } \\
\text { Cases }\end{array}$ & $\begin{array}{l}\text { VAS before } \\
\text { Treatment }\end{array}$ & $\begin{array}{l}\text { No. of } \\
\text { Cases }\end{array}$ & $\begin{array}{c}\text { VAS after } \\
\text { Treatment }\end{array}$ \\
\hline 2 & 5 & 2 & 0 \\
\hline 10 & 6 & $\begin{array}{l}1 \\
6 \\
2 \\
1\end{array}$ & $\begin{array}{l}0 \\
1 \\
2 \\
4\end{array}$ \\
\hline 17 & 7 & $\begin{array}{c}2 \\
12 \\
1 \\
1 \\
1\end{array}$ & $\begin{array}{l}0 \\
1 \\
2 \\
3 \\
6\end{array}$ \\
\hline 47 & 8 & $\begin{array}{c}11 \\
21 \\
7 \\
4 \\
3 \\
1\end{array}$ & $\begin{array}{l}0 \\
1 \\
2 \\
3 \\
4 \\
6\end{array}$ \\
\hline 10 & 9 & $\begin{array}{l}3 \\
5 \\
1 \\
1\end{array}$ & $\begin{array}{l}0 \\
1 \\
2 \\
3\end{array}$ \\
\hline 4 & 10 & $\begin{array}{l}1 \\
1 \\
1 \\
1\end{array}$ & $\begin{array}{l}0 \\
1 \\
2 \\
5\end{array}$ \\
\hline \multicolumn{4}{|c|}{ Table 1: Results } \\
\hline
\end{tabular}

\section{DISCUSSION}

Low back pain is most often associated with quadratus lumborum muscle Trigger Points (TPs), often with an accompanying lumbar multifidi and superficial paraspinal muscle TPs. In addition to poor body mechanics, structural asymmetries such as scoliosis and pelvic torsion contribute to chronic shortening of the quadratus lumborum muscle. TPs in the psoas muscle often develop when the quadratus lumborum is involved and the psoas muscle itself is an often overlooked cause of back pain. The quadratus lumborum muscle because of its attachment to the pelvis tends to put the pelvis into anterior rotation when it is shortened. Treating quadratus TPs usually requires treating the hamstring muscles as well, because they are under constant tension when the pelvis is anteriorly rotated.

Piriformis syndrome can be the result of buttock and hip pain caused by TPs in the piriformis muscle alone or by compression of the sciatic nerve by the shortened and thickened piriformis muscle. When the sciatic nerve is compressed, pain may be felt in the distribution of the sciatic nerve involving the back of the thigh, the entire leg below the knee and the foot. This is another under-recognized cause of hip, leg and foot pain that is rapidly reversed when the TPs are injected with local anaesthetic, a valuable diagnostic test. Trigger points in glutei muscles also represent as low back pain. Latissimus dorsi, the muscle connecting lower back to the upper body also can have trigger points with referred pain into the back. After treatment 80 cases had permanent modulation of pain, 2 cases came back with pain, 4 cases did not have much relief, 3 cases did not come for follow-up, in one case pain decreased but burning sensation persisted.

\section{CONCLUSION}

Dry Needling is a modality to facilitate a quick response to significantly reduce pain, so a person could return to function. It is minimally invasive, cheap, carries low risk, reduces medication. It is an excellent adjuvant therapy in the management of chronic painful conditions like Low Back Ache, etc.

\section{REFERENCES}

1. Hong CZ. Treatment of myofascial pain syndrome. Curr Pain Headache Rep 2006;10(5):345-9.

2. Baldry P. Acupuncture, trigger points and musculoskeletal pain, 3rd ed. Churchill Livingstone 2005.

3. Cagnie B, Barbe T, De Ridder E, et al. The influence of dry needling of the trapezius muscle on muscle blood flow and oxygenation. J Manipulative Physiol Ther 2012;35(9):685-91.

4. Shah JP, Phillips T, Danoff JV, et al. An in vivo microanalytical technique for measuring the local biochemical milieu of human skeletal muscle. J Appl Physiol 2005;99(5):1977-84.

5. Shah JP, Gilliams EA. Uncovering the biochemical milieu of myofascial trigger points using in vivo microdialysis: an application of muscle pain concepts to myofascial pain syndrome. J Bodyw Mov Ther 2008;12(4):371-84.

6. Hsieh YL, Yang SA, Yang CC, et al. Dry needling at myofascial trigger spots of rabbit skeletal muscles modulates the biochemicals associated with pain, inflammation, and hypoxia. Evid Based Complement Alternat Med 2012;2012:342165.

7. Chou LW, Kao MJ, Lin JG. Probable mechanisms of needling therapies for myofascial pain control. Evid Based Complement Alternat Med 2012;2012:705327. 
8. Chu J, Schwartz I. The muscle twitch in myofascial pain relief: effects of acupuncture and other needling methods. Electromyogr Clin Neurophysiol 2002;42(5):307-11.

9. Srbely JZ, Dickey JP, Lee D, et al. Dry needle stimulation of myofascial trigger points evokes segmental antinociceptive effects. J Rehabil Med 2010;42(5):463-8.
10. Hsieh YL, Kao MJ, Kuan TS, et al. Dry needling to a key myofascial trigger point may reduce the irritability of satellite MTrPs. Am J Phys Med Rehabil 2007;86(5):397403.

11. Visual analog scale and verbal pain intensity scale. From pain management: theory and practice, edited by RK Portenoy, RM Tanner, copyright by Oxford University Press, Inc. Used by permission of Oxford University Press 1996. 